\title{
11. TUTORIALS
}

\section{A multimedia program to educate the public about mental and addictive disorders}

\author{
JOEL EPSTEIN, LINDA SAGE, and DANNY WEDDING \\ Missouri Institute of Mental Health, St. Louis, Missouri
}

\begin{abstract}
The Mental Health Studios is an interactive multimedia program designed to educate the public about the biological basis of mental and addictive disorders. Using sound, text, graphics, charts, and video, the software provides detailed scientific information about the brain and depression, bipolar disorder, schizophrenia, anxiety disorders, and substance abuse. An evaluation study of a permanent display at the St. Louis Science Center revealed that most visitors spent less than 5 min with the computer program but nevertheless demonstrated significant changes in attitude toward people with mental and addictive disorders. Senior high-school students who interacted with the program for 20 min experienced even greater attitude changes, and their knowledge about mental and addictive disorders also increased significantly.
\end{abstract}

The Missouri Institute of Mental Health developed an exhibit that educates the public about mental illness and substance abuse. Entitled "Mental Health: The Brain Matters," it consists of a wall display, together with an interactive, multimedia computer program, the Mental Health Studios. The exhibit is on permanent display at the Med Tech Gallery of the St. Louis Science Center (SLSC), and a traveling version educates clergy and lay persons at national and regional faith conventions.

The exhibit was developed in response to the public's lack of knowledge about mental and addictive disorders. Previous surveys revealed a substantial amount of misunderstanding among many Americans regarding mental illness. Common misconceptions include the belief that people with schizophrenia have "split personalities," that mental illness results from emotional weakness, and that bad parenting or sinful behaviors can lead to mental illness (University of Missouri-Columbia, 1989). In addition to a lack of basic knowledge, many people harbor negative attitudes toward those with mental illness. For example, Borinstein (1992) reported that people are more comfortable in the presence of a blind person than in the

The exhibit was developed in collaboration with the St. Louis Science Center and Pathways to Promise, a nonprofit organization in St. Louis that educates faith groups about mental illness. A $\$ 170,000 \mathrm{Sci}-$ ence Education Partnership Award from the National Institute of Mental Health funded the project. The authors wish to thank Richard Evenson and William Chase for their assistance in preparing this manuscript. Correspondence concerning this article should be addressed to J. Epstein, Missouri Institute of Mental Health, 5247 Fyler Avenue, St. Louis, MO 63139-1361 (e-mail: projective@aol.com). presence of a person with a mental illness. Moreover, people are much more likely to welcome a new school or hospital in their neighborhood than to welcome apartments for people with mental illness (Borinstein, 1992).

\section{THE MULTIMEDIA PROGRAM}

The Mental Health Studios program combines sound, text, graphics, charts, and video to provide detailed scientific information about the brain and psychiatric disorders. We used an interactive, multimedia format rather than a videotape, because touch-screen programs allow users to control the pace of a presentation, view only those portions of interest to them, and repeat segments as often as they desire. We hoped that a program that combined different sensory stimuli and adjusted to each user's knowledge, speed, and motivation would help participants retain the material we presented (Katz, 1990; Matta \& Kern, 1991; Wade, 1990).

We developed the program over a 12-month period. First, we formulated the following three core messages: (1) Mental and addictive disorders are biologically based; (2) anyone can develop a mental or addictive disorder; and (3) mental and addictive disorders can be treated. To flesh out these messages, we created an extensive outline by gathering and reviewing information from journals, books, and literature from mental-health organizations. Because observations at the SLSC suggested that visitors typically spend only three minutes at any exhibit, we decided to deliver the most important information early in the program and to present supporting information later. It took three months to develop a creative approach that 
would present this material in an entertaining yet educational manner.

A professional scriptwriter helped us transform our outline into a narrative, producing a script that underwent numerous revisions after feedback from professionals and mental-health consumers. A commercial artist created storyboards from the script, and another artist created many of the graphics. We also enlisted the help of a professional narrator, a video crew, and a photographer. The National Institute of Mental Health, the National Institute on Drug Abuse, local hospitals, schools, and even an amusement park provided additional materials. Throughout the asset acquisition phase, we were careful to balance the racial and gender mix of persons displayed within the program.

Eight months into the project, we began to write the computer program. For the next four months, we converted the script and its accompanying audio and visual assets into an interactive multimedia program. We used Authorware Professional (Macromedia, San Francisco, CA) on a Macintosh Quadra 950 with $72-\mathrm{Mb}$ RAM and a 1.2-Gb hard drive. The final product was a $92-\mathrm{Mb}$ file, together with over $175 \mathrm{Mb}$ of supporting video. After completely debugging the program, we produced a PC-compatible version.

The underlying metaphor of the Mental Health Studios is one of a multistory building housing artists' workshops. Each workshop represents a different psychiatric disorder and is associated with a different artistic medium. For example, the second floor is a woodworking studio that teaches about depression. Other studios convey information about bipolar disorder, schizophrenia, anxiety disorders, and substance abuse. Within each studio are various brightly colored objects which, when touched, present detailed information about the disorder. For example, touching a portrait on the wall leads to a brief video clip of a consumer speaking about her mental illness. By fully exploring each studio, a user can learn about each disease's symptoms, epidemiology, etiology, and treatment options. An additional module, which presents an overview of the brain and its functioning, rounds out the program's content. It takes nearly two hours to view every studio and its associated submodules.

\section{ABILITY TO CHANGE ATTITUDES}

\section{Measures}

After the exhibit was installed at the SLSC, we assessed the program's ability to change visitors' attitudes toward people with mental and addictive disorders. We used a 27-item Likert-type questionnaire that assessed acceptance of the program's three core messages. The measure was piloted and revised twice before the actual study was conducted. The final version had a reliability coefficient of .89 .

\section{Subjects}

Of a total of 162 randomly selected participants who agreed to complete the questionnaire, $83(51 \%)$ were female; $74 \%$ of the subjects were Caucasian, $17 \%$ were
African American, $5 \%$ were Hispanic, and $4 \%$ were Asian. In terms of education, $4 \%$ of the participants had doctorates, $10 \%$ had master's degrees, $34 \%$ had college degrees, $32 \%$ had some college education, $17 \%$ had graduated high school, and 3\% had not completed high school. Mental-health or health-care providers comprised $51 \%$ of the sample. These demographics roughly mirror those of the SLSC visitors overall, except that there was a slightly higher proportion of African Americans, as well as many more health professionals than would be expected. The nature of the exhibit and its location in the Med Tech Gallery most likely account for the fact that it attracted so many health-care providers.

\section{Design}

The pre/post group ( $n=52$ ) completed the questionnaire immediately before and immediately after interacting with the Mental Health Studios program. The postonly group $(n=54)$ answered the questionnaire only after interacting with the program. The subjects in the control group $(n=56)$ took the questionnaire in a separate gallery at the SLSC, and did not interact with the multimedia program.

\section{Results}

The average time spent using the program was 4.24 min, with a range of $1-25 \mathrm{~min}$. This is actually slightly longer than expected, and as a result, the exhibit has one of the longest visit times in the Med Tech Gallery.

Despite their relatively brief exposure to the materials, the subjects comprising the experimental group demonstrated a significant improvement in their attitudes toward persons with mental illness. The total possible score on the questionnaire was 135 ; the pre/post group had a pretest average of $106.19(S D=13.43)$ and a posttest mean of $111.15(S D=10.22)$. The paired $t$ test value of these means is $4.76(p<.001)$.

The post-only group served as a control for pretest sensitization. On the questionnaire, the mean score of the subjects in this group was $108(S D=11.28)$. This average does not significantly differ from the posttest scores of the subjects in the pre/post group $(t=.382, p=.538)$. These results suggest that the positive increase in the pre/ post group was not merely a result of pretest sensitization.

The control group served as a control for the effects of self-selection by those who were interested in interacting with the mental-health exhibit. The mean questionnaire score of the subjects in this group was $102.95(S D=9.18)$, which is not significantly different from the pretest scores $(t=1.4, p=.166)$. This finding minimizes the likelihood that the significant changes in attitude that occurred in our experimental group resulted from selection bias.

The magnitude of the mean difference from pretest to posttest is not large (4.76), but it is similar to that obtained by Bairan and Farnsworth (1989), Jaffe, Mooz, and Avram (1979), and Meltzer and Grigarian (1972), and larger than that obtained by Keane (1990). The mean score of the post-only group in our study did not differ significantly from the pretest score of the pre/post group (un- 
correlated $t=1.4, p<.16$ ), but was significant when compared with the control group (uncorrelated $t=2.57$, $p<.01)$. Since the ratings were gathered over a period of several days, such differences from the experimental group are likely a result of sampling differences. Table 1 shows the relative contributions of individual items from pre- to posttest. Although the variance explained is obviously small, as are the absolute item changes, the results are similar to those of earlier studies of educational effects on attitude change (Bairan \& Farnsworth, 1989; Jaffe et al., 1979; Meltzer \& Grigarian, 1972).

\section{Educating High-School Students}

The positive findings from our initial evaluation at the SLSC prompted us to conduct a second, more structured, analysis at Francis Howell Senior High School in St. Charles, Missouri. In particular, we wanted to see how students would respond in a setting in which there was more time to interact with the multimedia program.

\section{Measures}

We revised our original questionnaire by retaining from the SLSC study 13 items that proved to be most sensitive

Table 1

Relative Contributions of Individual Items From Pretest to Posttest

\begin{tabular}{|c|c|c|c|c|c|}
\hline \multirow{3}{*}{\multicolumn{2}{|c|}{ Item }} & \multicolumn{4}{|c|}{ Pre- and Postscores by Item } \\
\hline & & \multicolumn{2}{|c|}{ Prescore } & \multicolumn{2}{|c|}{ Postscore } \\
\hline & & $M$ & $S D$ & $M$ & $S D$ \\
\hline 1. & Mental illness is a brain disease. & 3.46 & .99 & 4.11 & .87 \\
\hline 2. & $\begin{array}{l}\text { Specific mental disorders may be linked to a lack of } \\
\text { concentration and discipline. }\end{array}$ & 3.50 & .98 & 3.65 & .96 \\
\hline 3. & $\begin{array}{l}\text { People become mentally ill because of a } \\
\text { chemical imbalance in their brain. }\end{array}$ & 3.75 & .81 & 4.07 & .70 \\
\hline 4. & Mental disorders are caused by moral weakness. & 4.09 & .89 & 4.40 & .66 \\
\hline 5. & $\begin{array}{l}\text { Specific mental disorders may be linked to changes in } \\
\text { the brain's biochemistry. }\end{array}$ & 3.98 & .69 & 4.01 & .69 \\
\hline 6. & $\begin{array}{l}\text { Mental disorders could be avoided if parents loved their } \\
\text { children more. }\end{array}$ & 3.96 & 1.17 & 4.13 & 1.08 \\
\hline 7. & $\begin{array}{l}\text { Mental illness is a disease that is just like any other } \\
\text { illness. }\end{array}$ & 3.53 & .97 & 3.63 & .99 \\
\hline 8. & $\begin{array}{l}\text { People become mentally ill to avoid dealing with } \\
\text { everyday problems. }\end{array}$ & 4.07 & .85 & 4.17 & .75 \\
\hline 9. & Mental disorders are related to a person's genetic make-up. & 3.73 & .74 & 3.96 & .73 \\
\hline 10. & Mental illness is treatable. & 4.15 & .57 & 4.28 & .69 \\
\hline 11. & Psychotherapy for people with mental illness is a racket. & 3.88 & .98 & 4.00 & .88 \\
\hline 12. & $\begin{array}{l}\text { Medication can be successfully used for treating } \\
\text { mental illness. }\end{array}$ & 3.84 & .80 & 4.13 & .62 \\
\hline 13. & $\begin{array}{l}\text { As far as treatment is concerned, there is little we can } \\
\text { do for people who have mental illnesses. }\end{array}$ & 4.07 & .83 & 4.26 & .62 \\
\hline 14. & $\begin{array}{l}\text { People with mental illness can lead a normal life after } \\
\text { receiving proper treatment. }\end{array}$ & 3.82 & .87 & 4.09 & .53 \\
\hline 15. & $\begin{array}{l}\text { Modern medical practice demonstrates that successful } \\
\text { treatments for mental iliness are possible. }\end{array}$ & 4.00 & .74 & 4.19 & .59 \\
\hline 16. & $\begin{array}{l}\text { People with mental illness could lead a normal life } \\
\text { if they would just try harder. }\end{array}$ & 3.63 & 1.12 & 3.75 & .96 \\
\hline 17. & $\begin{array}{l}\text { Medication is used mostly to keep mental patients } \\
\text { sedated. }\end{array}$ & 3.63 & 1.01 & 3.86 & .74 \\
\hline 18. & Mental illness is rarely treated successfully. & 3.84 & .93 & 4.25 & .68 \\
\hline 19. & Anyone can develop a mental illness. & 3.88 & .78 & 4.21 & .66 \\
\hline 20. & Only adults can develop a mental illness. & 4.23 & .75 & 4.40 & .49 \\
\hline 21. & $\begin{array}{l}\text { Children become mentally ill only if their parents were } \\
\text { mentally ill. }\end{array}$ & 4.11 & .80 & 4.26 & .59 \\
\hline 22. & $\begin{array}{l}\text { Women executives are more likely to develop a mental } \\
\text { illness than are male executives. }\end{array}$ & 4.01 & .85 & 4.19 & .74 \\
\hline 23. & $\begin{array}{l}\text { Only people who have abused drugs can develop a mental } \\
\text { illness. }\end{array}$ & 4.36 & .65 & 4.34 & .59 \\
\hline 24. & $\begin{array}{l}\text { Blue-collar workers are more likely than white-collar } \\
\text { workers to develop a mental illness. }\end{array}$ & 3.96 & .94 & 4.13 & .76 \\
\hline 25. & People of any profession can develop a mental illness. & 4.26 & .62 & 4.25 & .71 \\
\hline 26. & $\begin{array}{l}\text { The majority of people who have mental disorders are } \\
\text { poor. }\end{array}$ & 4.13 & .84 & 4.23 & .70 \\
\hline 27. & $\begin{array}{l}\text { Being lazy has nothing to do with whether a person } \\
\text { develops a mental disorder. }\end{array}$ & 4.09 & .82 & 4.07 & .88 \\
\hline
\end{tabular}


to change, and by adding 9 items from a 1989 Robert Wood Johnson-funded study of public attitudes toward mental illness (Borinstein, 1992). The final questionnaire used Likert-scaled items with anchors ranging from strongly agree to strongly disagree. The range of scores on this questionnaire was $22-110$.

We also developed a second questionnaire to assess the students' knowledge about mental illness. Questions on this 27-item multiple-choice test were gleaned from the content of the Mental Health Studios program.

\section{Subjects}

A total of 121 seniors from a local high school agreed to participate in this study. Of these students, $57 \%$ were female, $93 \%$ were white, and $29 \%$ had a family member or friend who had been treated for a mental illness.

\section{Design}

The students came to the school's library in groups of three and viewed the Mental Health Studios program jointly. Individually, the students filled out the questionnaires immediately before and after interacting with the program. A control group for the effects of testing was not included because sensitization by pretesting was not observed during the evaluation at the SLSC.

\section{Results}

Supporting the findings at the SLSC, interacting with the Mental Health Studios produced improvements in attitudes toward persons with mental illness. The students' mean score on the pretest for attitudes was 76.23 , and on the posttest was 83.72. This 7.5-point gain was significant $(t=10, p<.001)$. Similarly, the students' mean score for the pretest for content items was 16.09 , and for the post test was 18.65 . This 2.56 -point increase was also significant $(t=9.85, p<.001)$.

The high-school data corroborate the findings at the SLSC. However, the effects of our intervention were more substantial in the high-school students. Two likely explanations are that (1) the high-school students had more time to learn from and be influenced by the exhibit; and (2) these students were less sophisticated and less educated than SLSC visitors, and generally had less favor- able attitudes toward people with mental illness to begin with.

\section{Future Directions}

The evaluation data indicate that the Mental Health Studios program has the potential to change public attitudes toward persons with psychiatric disorders and to increase knowledge about the biological basis of mental illness and substance abuse. We therefore believe that the program will be valuable in museums, schools, and other educational settings. The Mental Health Studios program will be available on CD-ROM by the end of 1994. We intend to continue our efforts to produce other mentalhealth-related multimedia presentations. An important area of further research will be in the evaluation of the effectiveness of multimedia methods of information delivery, as opposed to alternative methods.

\section{REFERENCES}

Bairan, A., \& Farnsworth, B. (1989). Attitudes toward mental illness: Does a psychiatric nursing course make a difference? Archives of Psychiatric Nursing, 6, 351-357.

Borinstein, A. B. (1992, Fall). Public attitudes toward persons with mental illness. Health Affairs, pp. 186-196.

JAFFE, Y., Mooz, B., \& AVRaM, L. (1979). Mental hospital experience, classroom instruction, and change in conceptions and attitudes towards mental illness. British Journal of Medical Psychology, 52, 253-258.

KATZ, N. (1990). Problem solving and time: Functions of learning style and teaching methods. Occupational Therapy Journal of Research, 10, 221-236.

Keane, M. (1990). Contemporary beliefs about mental illness among medical students: Implications for education and practice. Academic Psychiatry, 14, 172-177.

MATTA, K.; \& KERN, G. (1991). Interactive videodisc instruction: The influence of personality on learning. International Journal of ManMachine Studies, 35, 541-552.

Meltzer, M. L., \& Grigarian, H. M. (1972). Effect of psychiatric education on attitudes of medical students to mental illness. Psychiatry, 35, 195-204.

University of Missouri-Columbia (1989). Missouri mental health attitudes survey. (Available from the Media Research Center, University of Missouri-Columbia, Columbia, MO)

WADE, T. C. (1990). Patients may not recall disclosure of risk of death: Implications for informed consent. Medicine, Science \& the Law, 30, 259-262.

(Manuscript received November 18, 1994; revision accepted for publication January $31,1995$. 